\title{
RETRACTED ARTICLE: The Neuroprotective Effect of Histamine H4 Receptor Antagonist on Dopaminergic Neurons in Parkinson's Disease
}

\author{
Xu Cao ${ }^{1,2}$ (D) $\cdot$ Haibing Xiao ${ }^{3} \cdot$ Miaojuan Yang $^{2} \cdot$ Xiaowu Chen $^{2}$
}

Received: 13 June 2018 / Accepted: 11 December 2018 / Published online: 23 February 2019

(C) Springer Science+Business Media, LLC, part of Springer Nature 2019

The authors have retracted this article [1] because it shows significant overlap with a previously published article by Zhou et al. [2]. All authors agree to this retraction. The online version of this article contains the full text of the retracted article as electronic supplementary material.

1. Cao X, Xiao H, YangMet al. (2019) J Mol Neurosci. https://doi.org/10.1007/s12031-018-1242-8.

2. Zhou P, Homberg JR, Fang Q et al. (2019) Histamine-4 receptor antagonist JNJ7777120 inhibits pro-inflammatory microglia and prevents the progression of Parkinson-like pathology and behaviour in a rat model. Brain, Behavior, and Immunity 76:61-73.

Publisher's Note Springer Nature remains neutral with regard to jurisdictional claims in published maps and institutional affiliations.

Electronic supplementary material The online version of this article (https://doi.org/10.1007/s12031-018-1242-8) contains supplementary material, which is available to authorized users.

\footnotetext{
$\mathrm{Xu}$ Cao

caoxshzhugh@163.com

1 Department of Neurology, Shenzhen University General Hospital, Shenzhen University Clinical Medical Academy, Shenzhen, China

2 Department of Neurology, Shenzhen People's Hospital, Jinan University, Shenzhen, China

3 Department of Neurology, The University of Hong Kong - Shenzhen Hospital, Shenzhen, China
} 